Media Publikasi Promosi Kesehatan Indonesia The Indonesian Journal of Health Promotion

\title{
Perilaku Menyusui Eksklusif Di Kalangan Tenaga Kesehatan Di Kota Makassar
}

\author{
Exclusive Breastfeeding Behavior Among Health WRorker In Makassar City \\ Fitriyah Amiruddin \\ Jurusan Promosi Kesehatan, STIK Tamalatea Makassar \\ Email : fitriyah@stiktamalateamks.ac.id
}

\begin{abstract}
Abstrak
Salah satu tantangan bagi ibu memberikan ASI Ekslusif bagi bayinya adalah kesibukan bekerja. Penelitian bertujuan untuk menilai perilaku petugas kesehatan sebagai seorang ibu dalam memberikan ASI Eksklusif dan kaitannya dalam perilaku mempromosikan ASI Esklusif kepada klien. Jenis penelitian ini adalah kulitatif dengan desain studi kasus. Informan sebanyak 10 orang tenaga kesehatan dengan berbagai latar belakang pendidikan. Teknik pengumpulan data menggunakan wawancara mendalam dan observasi. Hasil penelitian menunjukkan semua informan berniat menyusui eksklusif karena mengetahui manfaat ASI bagi bayi. Namun, tidak semua informan berhasil memberikan ASI Eksklusif. Pengalaman menyusui di masa lampau mempengaruhi perilaku sekarang. Kondisi fasilitas di tempat kerja cukup mendukung bagi ibu untuk tetap memberikan ASI meskipun telah kembali bekerja. Perilaku tenaga kesehatan yang berhasil memberi ASI Eksklusif kepada bayinya dapat menjadi role model bagi klien dan masyarakat umum, serta menjadikan tenaga kesehatan tersebut lebih percaya diri dalam mengedukasi klien agar menyusui Eksklusif. Saran peneliti agar dukungan kepada tenaga kesehatan yang menyusui lebih ditingkatkan berupa motivasai moral dari pimpinan.
\end{abstract}

Kata Kunci: Promosi ASI, ASI eksklusif, tenaga kesehatan

\begin{abstract}
One of the challenges for mothers to give exclusive breastfeeding for the baby is busy work. The study aims to assess the behavior of health workers as a mother in relation to exclusive breastfeeding and exclusive breastfeeding in promoting behaviors to clients. This type of research is qualitative with case study design. Informants were 10 health worker with various educational backgrounds. The technique of collecting data using in-depth interviews and observation. The results showed all respondents intend to breastfeed exclusively for knowing the benefits of breastfeeding for babies. However, not all informers managed to exclusive breastfeeding. Breastfeeding experience in the past affect the present behavior. Working place supportive enough for the mother to keep breastfeeding even though it has returned to work. Behavioral health workers who managed to give exclusive breastfeeding their babies can become role models for clients and the general public, and to make the health workers more confident in educating clients to breastfeed exclusively. The researchers suggest that support for health workers who breastfeed for more enhanced form of moral motivation from the leaders.
\end{abstract}

Keywords: Breastfeeding promotion, exclusive breastfeeding, health worker 


\section{PENDAHULUAN}

Salah satu tantangan bagi ibu memberikan ASI Ekslusif bagi bayinya adalah kesibukan bekerja. Berdasarkan survei Badan Pusat Statistik (BPS) tahun 2013, jumlah angkatan kerja wanita terus meningkat setiap tahunnya. Saat ini dari 114 juta jiwa (94\%), 38\% diantaranya adalah pekerja perempuan (43,3 juta jiwa) yang 25 juta diantaranya berada pada usia reproduktif [1]. Secara fisiologis kelompok pekerja perempuan mengalami siklus haid, hamil dan menyusui yang memerlukan fasilitasi agar pekerjaan tidak terganggu dan kondisi fisik lainnya tidak mengurangi kinerja [2].

Ibu bekerja rata-rata selama 8 jam sehari. Hal ini berdampak kurangnya waktu untuk menyusui anaknya. Keadaan tersebut diperparah dengan minimnya kesempatan untuk memerah ASI di tempat kerja, tidak tersedianya ruang ASI, serta kurangnya pengetahuan ibu bekerja tentang manajemen laktasi [2]. Data Riskesdas 2013 menunjukkan hanya 38 perempuan karir yang memberikan ASI eksklusif bagi bayinya [3].

ASI mengandung zat gizi tinggi yang sangat bermanfaat untuk kesehatan bayi. Badan Kesehatan Dunia (WH0), merekomendasikan bayi mendapat ASI eksklusif selama 6 bulan. Dari 136,7 juta bayi lahir diseluruh dunia hanya 32,6\% dari mereka yang disusui secara eksklusif dalam 6 bulan pertama. Sedangkan di negara industri, bayi yang tidak diberi ASI Eksklusif lebih banyak meninggal dari pada bayi yang diberi ASI Eksklusif. Sementara di negara berkembang hanya 39\% ibu-ibu yang memberikan ASI Eksklusif (UNICEF, 2013).

Jumlah bayi yang diberi ASI eksklusif di Sulawesi Selatan tahun 2008 yaitu 57,48\% dan tahun 2007 yaitu 57,05\%. Bisa dikatakan Inisiasi Menyusui Dini (IMD) belum dilaksanakan dengan baik. Bahkan rata-rata lama balita yang diberi ASI di Sulawesi Selatan selama 2006-2010 mengalami tren penurunan. Menurut Profil Kesehatan Sulawesi Selatan 2013, cakupan ASI eksklusif di Makassar pada tahun 2010, 2011, 2012 masih rendah. Pada tahun 2010 pencapaian ASI adalah 91,12\%, pada tahun 2011 mengalami penurunan yaitu 34,8\% dan pada tahun 2012 mengalami sedikit peningkatan yaitu 63,7\%. Namun, pada tahun 2013 kembali mengalami penurunan, yaitu 61,3\% [4].

Tenaga kesehatan perempuan adalah role model, perilaku memberikan ASI Eksklusif akan memberikan manfaat terhadap diri dan bayinya. Mereka juga akan meningkatkan kepatuhan dari perempuan yang memahami manfaat ASI Eksklusif tapi tidak ingin mempraktekkannya karena tenaga kesehatan wanita yang mengajari mereka juga tidak melakukannya sehingga menyebabkan keraguan akan manfaat dari praktek menyusui Eksklusif [5].

Beberapa penelitian telah menunjukkan bahwa petugas kesehatan memainkan peran penting dalam keputusan dan perilaku ibu. Dukungan dan konseling dari penyedia layanan kesehatan dapat meningkatkan angka menyusui serta inisiasi dini, durasi menyusui, dan membuat ibu lebih percaya diri. Penelitian ini dilakukan untuk menilai bagaimana perilaku petugas kesehatan sebagai seorang ibu dalam memberikan ASI Eksklusif dan kaitannya dalam perilaku mempromosikan ASI Esklusif kepada klien ibu bekerja.

\section{METODE}

Penelitian ini merupakan jenis penelitian Kualitatif dengan pendekatan desain studi kasus. Penelitian dilakukan di kota Makassar, Sulawesi Selatan pada bulan Juni-Juli tahun 2016. Data dikumpulkan dengan teknik In-Depth Interview dan Observasi Data dianalisis dengan menggunakan domain analisis yakni dengan reduksi data, pengolahan data kemudian interpretasi data. Penyajian data dalam bentuk narasi, skema, bagan, tabel dan gambar.

\section{HASIL}

Hasil penelitian menjelaskan niat, kebiasaan, dan pengalaman menyusui tenaga kesehatan selain itu menjelaskan perilaku tenaga kesehatan dalam promosi ASI Eksklusif di kota Makassar. Informan dalam penelitian ini didapatkan dengan metode snowball, yang dimulai dari tenaga kesehatan yang juga ketua AIMI Sulsel. Informan sebanyak 10 orang 
tenaga kesehatan, yang terdiri dari 2 orang tenga kesehatan yang juga pengurus AIMI Sulsel , 7 orang lainnya tenaga kesehatan di RS Pemerintah, Balai Pelatihan Kesehatan dan Klinik Swasta.

Berdasarkan hasil wawancara dari 10 informan, ditemukan bahwa semua informan menyatakan bahwa mereka berniat untuk memberikan ASI Eksklusif kepada bayinya karena mengetahui tentang manfaat dari ASI untuk kesehatan bayi baru lahir dan kelebihan-kelebihan ASI dibandingkan susu formula. Hal ini terungkap dari hasil kutipan wawancara mendalam berikut ini:

“... kalau saya sih dasarnya itu memang berniat sekali kasi ASI untuk kesehatannya dia, untuk menjalin kasih sayang sama dia.."

$(N T, 27$ th)

Dari jawaban informan yang lain alasan memberikan ASI Eksklusif salah satunya karena keyakinan yang dipahami bahwa ASI adalah pemberian Tuhan, rejeki bagi bayi/anak, dan merupakan perintah Allah untuk menyusui bayi, dari sejak lahir hingga 2 tahun. Informan lain menyatakan bahwa fungsi payudara pada wanita itu adalah untuk menyusui, sehingga seorang perempuan bertugas menyusui anaknya. Seperti kutipan wawancara berikut ini:

“...setelah saya gagal baru saya belajar, ternyata banyak dalam Al Qur'an yang juga dijelaskan. Tapi yang saya pahami waktu itu semua yang diciptakan Allah ada gunanya, dan payudara diciptakan kenapa kepada para perempuan karena perempuan bertugas menyusui anaknya, bukan pada laki-laki, karna laki laki tidak menyusui bayinya"

(AA, 39 Tahun)

Sebagian besar informan menyatakan bahwa peran sebagi tenaga kesehatan merupakan faktor pendukung, bukan faktor utama yang melandasi mereka berniat dan berperilaku untuk memberikan ASI Eksklusif. Seperti kutipan wawancara berikut:

“Sebenarnya tdk ji juga iya, bukan itu motivasi utama, tapi ada juga sih. Kan nanti orang bilang apa. Maksudnya kita ingin jadi contoh, jadi role model. Malu dong kalau kita orang kesehatan, baru kita tdk menyusui. Apa katanya orang orang di sekitar kita yang tau persis tentang kita, kita bicara tentang ASI, baru ternyata kita tidak menyusui, tidak berjuang. Ada juga peran nya sih...Tapi bukan itu yg jadi motivasi utama"

Hal ini menunjukkan bahwa peran sebagai contoh di masyarakat atau role model yang dipahami oleh informan adalah faktor pendukung dalam perilaku menyusui Eksklusif. Ada perasaan malu dan khawatir akan penilaian orang lain jika tidak menyusui Eksklusif sementara ia adalah penganjur perilaku menyusui Eksklusif di masyarakat.

Sementara itu, ada informan yang tidak berhasil menyusui secara Eksklusif menyatakan dia tidak begitu peduli dengan tanggapan orang, yang terpenting anaknya sehat. Seperti kutipan wawancara berikut:

“...Cuek ja juga, saya yang kupikir itu anakku sehatji, karena alhamdulillah, anu ji toh, sehat ji juga dengan sufor"

Hal ini menunjukkan bahwa informan belum memahami bahwa dirinya adalah role model model di masyarakat. Perilakunya bisa saja menjadi alasan bagi masyarakat umum untuk tidak memberikan ASI Eksklusif. Berikut skema hasil wawancara dengan informan tentang pemahaman bahwa tenaga kesehatan adalah role model dalam perilaku menyusui Eksklusif:

Peneliti menggali informasi terkait kebiasaan tenaga kesehatan dalam menyusui Eksklusif, yaitu pengalaman 
atau perilaku menyusui di masa sebelumnya, pada informan yang telah memiliki anak lebih dari 1 orang. Tujuannya untuk melihat bagaimana perilaku di masa lampau tersebut memengaruhi perilakunya saat ini.

Salah seorang informan yang gagal memberikan ASI Eksklusif untuk anak pertama, kembali gagal memberikan ASI Eksklusif untuk anak kedua, alasannya kembali bekerja yang membuatnya menghentikan penyusuan sebelum 6 bulan dan praktik pemberian susu formula untuk menggantikan ASI Perah yang tidak mencukupi ketika informan meninggalkan bayinya bekerja. Seperti dalam kutipan wawancara berikut ini:

“..yang pertama memang, yang pertama kalau saya di rumah ASI, kalau ditinggalkan diperahkan, atau kalau tidak cukup dikasi itumi, susu formula...Yang kedua, dia memang dicampur, pernah kaya nya' dia menolak yang diperah, jadi kukasi formula lebih cepat"

Informan lain menyusui secara Eksklusif untuk anak pertama, karena merasakan manfaat ASI Eksklusif pada anak yang pertam sehingga berusaha untuk memberikan ASI Eksklusif untuk anak kedua. Seperti kutipan wawancara berikut ini:

"Karena saya sudah liat anakku yang pertama, betul2 dia sakit, sakit, tapi maksudnya tidak kaya anaknya orang yang kalau sakit kasian kaya bagaimana sekali. Apalagi saya anakku selama bayi kalau kaya flu ji tidak pernah kukasi obat, sedangkan imunisasi saja tdk kukasi obat.kasi nete saja turun sendiri, yang anak keduaku ini memang saya bertekad stok ASI karena saya mau praktek"

(NT, 27 Th)

Ada juga informan yang tidak berhasil memberikan ASI Eksklusif untuk anak pertama dan anak kedua, namun untuk anak yang ketiga ia berusaha untuk memberikan ASI Eksklusif dengan alasan agar lebih baik dari 2 orang anak sebelumnya. Sebagaimana hasil kutipan wawancara berikut ini:

"Yang pertama dan kedua tidak ASI Eksklusif, yang ketiga pi. Begitu selesai cuti, lepas tommi... sampai dua bulan ji. Setidaknya meningkat dari kakak nya..."

(NA, $31 \mathrm{Th}$ )

Dari 10 informan, 5 orang berhasil memberikan ASI Eksklusif sampai 6 bulan kepada bayinya (riwayat anak yang terakhir), sementara 5 orang lainnya ada yang hanya sampai usia 3, 4 dan 5 bulan. Informan yang tidak berhasil memberikan ASI Eksklusif menyatakan bahwa bayinya menolak disusui setelah ia mulai bekerja, hal tersebut terjadi karena pada saat ibu bekerja pengasuh memberikan ASIP (ASI Perah) menggunakan media dot (nipple), sehingga menyebabkan bayi bingung putting, menolak menyusu dan lama kelamaan produksi ASI menurun dan akhirnya berhenti.

Selain itu, pengasuh juga memberikan susu formula untuk dikonsumsi bayi ketika stok ASIP sudah habis. Hal tersebut menyebabkan lama kelamaan bayi lebih terbiasa dengan rasa susu formula yang manis, dan akhirnya lebih memilih susu formula dibanding ASIP. Berikut kutipan wawancara dengan informan:

“..selama 3 bulan cuti, full ASI setelah 3 bulan saya kembali kerja, masih ASI, tapi seiring saya masuk kerja, dia sudah menolakmi"

“...dia sukami sufor, mungkin karena rasanya lebih manis, ato apa, ASI ku juga perlahan lahan, kadang kupompa 3 sampai 4 kali sehari semakin berkurang... sampai habis..... sampai 5 bulanan masih dapat ASI ji, kadang juga tidak mau yang diperahkan, mungkin karena sudah mi coba susu formula”.

Informan yang berhasil memberikan ASI Eksklusif menyatakan bahwa lebih memilih untuk membawa bayinya 
ke kantor saat cuti kerja telah selesai dibanding memerah ASI. Alasannya, bisa menyusui bayi secara langsung tiap kali bayi menginginkannya. Selain itu kondisi tempat kerja cukup kondusif bagi ibu dan bayi, serta atasan yang mengijinkan untuk membawa bayi ke tempat kerja. Seperti kutipan wawancara berikut:

"Jadi usia 2 bulan habis cuti saya bawami ke kantor, menyusui kalau memang nangis toh, kalau tidak dikasi tidur lagi, kan bayi begitu masih banyak tidur, belum terlalu aktif ..."

Informan untuk menilai perilaku tenaga kesehatan dalam promosi ASI Eksklusif sebanyak 3 orang, terdiri dari 2 orang tenaga kesehatan yang merupakan pengurus AIMI Sulsel dan 1 orang bidan yang bertugas di ruang bersalin dan perawatan RS Pemerintah. Promosi ASI Eksklusif yang dilakukan oleh Informan pengurus AIMI Sulsel berupa konseling kepada ibu menyusui. Berikut kutipan wawancara dengan informan:

"Saya salah satu tim fasilitator untuk pelatihan konseling menyusui, kemudian...saya juga fasilitator untuk pelatihan spesialis konselor menyusui, ada lagi nama nya 4 in 1. Tapi kalau di AIMI kegiatannya yang saya biasa lakukan ... selain organisasi, kami melayani visit pasien, jadi kami mengkonseling ibu ibu menyusui. Kami di AIMI melayani home visit dan hospital visit untuk konseling menyusui"

Informan lainnya menyatakan upayanya dalam promosi ASI Eksklusif, khususnya di AIMI Sulsel yaitu menjadi fasilitator dalam kegiatan pelatihan, misalnya dalam pelatihan kelas edukasi AIMI, seperti kelas MP-ASI 1 \& 2 .

\section{PEMBAHASAN}

Pembahasan pada bagian ini, didasarkan pada beberapa temuan yang dapat dikatakan sebagai suatu kenyataan. Kenyataan-kenyataan itulah yang perlu dianalisis sehingga maksud-maksud penelitian ini lebih mempunyai arti. Penelitian ini menemukan bahwa niat tenaga kesehatan memberikan ASI Eksklusif dilatarbelakangi oleh pengetahuannya akan manfaat ASI Eksklusif untuk kesehatan bayi.

Niat tenaga kesehatan memberikan ASI Eksklusif kepada bayinya berupa tekad kuat tenaga kesehatan untuk menyelesaikan hambatan yang akan dihadapinya dalam menyusui Eksklusif, seperti ketika kembali bekerja setelah cuti melahirkan. Salah satu tantangan bagi ibu memberikan ASI Ekslusif bagi bayinya adalah kesibukan bekerja. Weber, Janson, Nolan, Wen, \& Rissel, (2011) menyatakan bahwa kembali bekerja adalah alasan utama berhenti menyusui, dari $60 \%$ wanita yang berniat terus menyusui namun hanya 40\% yang melakukannya [6]

Seperti dalam penelitian tentang perilaku menyusui ibu bekerja, bahwa ibu bekerja berhasil memberikan ASI eksklusif karena memiliki intensi untuk memberikan ASI eksklusif sejak hamil, sikap positif terhadap manfaat ASI, efikasi diri yang baik, dapat melakukan manajemen laktasi, dan mampu mengatasi hambatan. Norma yang dipersepsikan dan budaya yang tidak sesuai dengan perilaku pemberian ASI eksklusif tidak merubah intensi ibu [1].

Ibu bekerja yang berhasil memberikan ASI eksklusif memiliki sikap positif karena mempercayai manfaat ASI terutama bagi bayi. Kepercayaan akan manfaat ASI terbentuk karena ibu memiliki pengetahuan dari petugas kesehatan, buku, internet atau berdasarkan pengalaman. Peningkatan sikap positif dan penurunan sikap negatif dapat meningkatkan cakupan pemberian ASI eksklusif. Bila ibu telah memiliki sikap positif maka intensi untuk memberikan ASI eksklusif juga meningkat [7].

Faktor pemfasilitasi seperti cuti melahirkan, kondisi ruang kerja yang kondusif, ketersedian fasilitas yang mendukung seperti ruang Laktasi, dan sebagainya.

Dalam penelitian pada tenaga kesehatan yang menyusui didapatkan bahwa kebijakan terkait jam kerja setelah cuti hamil dan ketersediaan ruang laktasi di tempat kerja serta Rumah Sakit Sayang Ibu dan Bayi akan meningkatkan 
tingkat pemberian ASI eksklusif di kalangan petugas kesehatan wanita. Selain itu dapat meningkatkan cakupan pemberian ASI eksklusif di antara semua ibu menyusui yang meniru petugas kesehatan wanita sebagai role model dalam perilaku menyusui Eksklusif [5].

Salah satu alasan informan yang gagal memberikan ASI Eksklusif karena ASI yang dirasa kurang. Hasil penelitian serupa pada pekerja tekstil di Jakarta menunjukkan bahwa pada kelompok ibu yang gagal ASI eksklusif, pemberian ASI saja sudah berhenti diberikan sejak usia bayi 4 bulan yang selanjutnya ditambahkan dengan makanan prelakteal seperti susu formula, biskuit dan buah-buahan. Pada umumnya ibu beralasan karena bayi tidak cukup kenyang jika diberi ASI saja, namun mayoritas ibu juga menjawab karena alasan bekerja dan kuantitas ASI yang sedikit

Meskipun seorang perempuan adalah profesional di bidang medis, ia juga menghadapi kesulitan dalam menyusui, sehingga diperlukan lingkungan tempat kerja yang mendukung ibu tetap memberikan ASI kepada bayinya. Selama pendidikan kedokteran dan residensi, dokter diajarkan bahwa menyusui adalah yang terbaik untuk bayi, dengan pengecualian langka. Tapi bukti terkumpul bahwa ibu dokter memiliki niat untuk menyusui, namun mereka menghadapi hambatan yang signifikan untuk keberlanjutan menyusui [8].

Beberapa penelitian telah menunjukkan bahwa petugas kesehatan memainkan peran penting dalam keputusan dan perilaku ibu. Dukungan dan konseling dari penyedia layanan kesehatan dapat meningkatkan angka menyusui serta inisiasi dini, durasi menyusui, dan membuat ibu lebih percaya diri. Beberapa studi menemukan bahwa ibu-ibu sering melaporkan diberi informasi yang salah atau tidak lengkap, atau dokter yang apatis tentang menyusui selama kunjungan medis [8].

Prediktor terkuat dari advokasi menyusui dokter adalah perilaku menyusui pribadi atau istri mereka. Oleh karena itu, dampak perilaku menyusui tidak hanya terhadap kesejahteraan dokter dan keluarganya, tetapi juga kesehatan pasien mereka dan keluarga pasien. Meskipun tingkat inisiasi menyusui sangat baik, ibu dokter sebagai kelompok berisiko melakukan penghentian menyusui dini. Ibu dokter yang berusaha untuk mempertahankan menyusui setelah cuti melahirkan mengidentifikasi dua hambatan utama di tempat kerja: kurangnya waktu dan tempat yang memadai untuk memerah ASI. Demikian pula, alasan utama ibu dokter untuk menghentikan penyusuan khususnya antara 1 dan 12 bulan setelah melahirkan, terkait dengan pekerjaan [9].

\section{KESIMPULAN DAN SARAN}

Niat tenaga kesehatan memberikan ASI Eksklusif kepada bayinya dipengaruhi oleh pengethuannya akan manfaat ASI Ekskluif dan nilai yang dipahami. Selain itu, tanggungjawab moral sebagai tenaga kesehatan menjadi faktor pendukung. Pengalaman keberhasilan menyusui di masa lampau menjadi alasan untuk kembali memberi ASI Eksklusif kepada anak berikutnya. Perilaku tenaga kesehatan yang berhasil memberi ASI Eksklusif kepada bayinya dapat menjadi role model bagi klien dan masyarakat umum, serta menjadikan tenaga kesehatan tersebut lebih percaya diri dalam mengedukasi klien agar menyusui Eksklusif. Saran peneliti agar dukungan kepada tenaga kesehatan yang menyusui lebih ditingkatkan berupa motivasai moral dari pimpinan. Sehingga tenaga kesehatan berupaya menyusui Eksklusif dan memberikan edukasi kepada klien dengan lebih baik lagi

\section{DAFTAR PUSTAKA}

[1] D. N. Anggraeni, M. F., Herawati, S., \& Mustika, "PEMBERIAN ASI EKSKLUSIF BERDASARKAN STATUS BEKERJA IBU YANG MEMILIKI BAYI USIA 6-11 BULAN DI WILAYAH KERJA PUSKESMAS KARANGAWEN 1 KABUPATEN DEMAK," J. Kebidanan, vol. 4, no. 1, 2015. 
[3] Riskesdas, Riset Kesehatan Dasar Nasional (Riskesdas) tahun 2013. Jakarta: Badan Litbangkes, 2013.

[4] D. K. S. Selatan, “Profil kesehatan Sulawesi Selatan 2008,” Diperoleh dari http//dinkes-sulsel. go. id/new/images/ pdf/profil/profil\% 20kesehatan\% 20sulsel, vol. 20, no. 2008, p. 20, 2009.

[5] N. D. Gladzah, "Challenges of Exclusive Breastfeeding Among Female Health Workers in Two Hospitals in Accra," University of Ghana, 2013.

[6] C. Weber, D., Janson, A., Nolan, M., Wen, L. M., \& Rissel, “Female employees' perceptions of organisational support for breastfeeding at work: findings from an Australian health service workplace," Int. Breastfeed. J., vol. 6, no. 1, p. $1,2011$.

[7] M. Mutuli, L., \& Walingo, "Influence of Psychosocial Factors on Breastfeeding Behavior of Mothers in Kakamega Central District, Kenya," ANNALS OF NUTRITION AND METABOLISM, Kenya, 2013.

[8] S. Britton, C., McCormick, F., Renfrew, M., Wade, A., \& King, "upport for breastfeeding mothers (Review),” 2007.

[9] J. R. Sattari, M., Levine, D., Neal, D., \& Serwint, "Personal breastfeeding behavior of physician mothers is associated with their clinical breastfeeding advocacy," Breastfeed. Med., vol. 8, pp. 31-37, 2013. 